\title{
Neck Injury Comorbidity in Concussion-Related Emergency Department Visits: A Population-Based Study of Sex Differences Across the Life Span
}

\author{
Mitchell Sutton, MSc, ${ }^{1,2}$ Vincy Chan, $\mathrm{PhD},{ }^{1}$ Michael Escobar, $\mathrm{PhD}, 2$ Tatyana Mollayeva, MD, $\mathrm{PhD}, 1,3$ \\ Zheng $\mathrm{Hu}, \mathrm{MSc}^{2}$, and Angela Colantonio, $\mathrm{PhD}^{1-5}$
}

\begin{abstract}
Background: The cervical spine region can be especially vulnerable to concurrent injury in concussion, with research suggesting that females may be at greater risk due to their weaker and anatomically distinct necks. The main objective of our research was to study sex differences in the rate of neck injury comorbidity across the life span among patients with a concussion diagnosis in the emergency department (ED) setting, by cause of injury (motor vehicle collisions [MVC] and sports).

Materials and Methods: All patients with a first concussion-related ED visit between fiscal years 2002/2003 and 2011/2012 (inclusive) in Ontario were identified in population-based health administrative data using the International Statistical Classification of Diseases and Related Health Problems, Tenth Revision, Canada (ICD10-CA) codes. Age-dependent odds ratios of comorbid neck injury for sex were estimated using polynomial multivariable logistic regression models, adjusting for sociodemographic characteristics.

Results: Females with a concussion had significantly higher odds of sustaining a comorbid neck injury between the ages of 5-49 years for all concussion-related ED visits, 15-49 years for MVC-related concussion ED visits, and 10-39 years for sports-related concussion ED visits, holding all other covariates in the model constant.

Conclusions: These results support the consideration of increased screening for comorbid neck injuries, particularly for females, to allow for early intervention. Furthermore, the increased risk of comorbid neck injury in females with a concussion-related ED visit was age-dependent, with the interaction between sex and age following a nonlinear trend. As such, future studies on concussions should consider linear and nonlinear sex and age interactions.
\end{abstract}

Keywords: concussion, neck injury, sex, motor vehicle, sports

\section{Introduction}

$\mathbf{T}$ RAUMATIC BRAIN INJURY (TBI) remains a major cause of death and disability in the United States, ${ }^{1}$ with $\sim 3.5$ million new injuries occurring each year ${ }^{2}$ with an annual estimated economic cost of more than $\$ 70$ billion (including both indirect and direct medical costs). ${ }^{3}$ The majority of injuries $(75 \%)$ are mild in severity ${ }^{2}$ and are frequently referred to as concussions. ${ }^{4}$ The overall incidence of TBI is higher among males $^{2}$; however, clinical studies have shown that females are at a higher risk of concussions in sports with similar rules. ${ }^{5-9}$ Furthermore, length to recovery post-injury has been found to be longer among females, who are also more likely to have persistent symptoms for more than a month. ${ }^{10,11}$ To date, although there has been a plethora of research on TBI and concussion, there is a paucity of studies assessing the prevalence

\footnotetext{
${ }^{1}$ Toronto Rehabilitation Institute-University Health Network, Toronto, Canada.

${ }^{2}$ Dalla Lana School of Public Health, University of Toronto, Toronto, Canada.

${ }^{3}$ Department of Occupational Sciences and Occupational Therapy, University of Toronto, Toronto, Canada.

${ }_{5}^{4}$ Rehabilitation Sciences Institute, University of Toronto, Toronto, Canada.

${ }^{5}$ Institute for Clinical and Evaluative Sciences, Toronto, Canada.
}

(C) Mitchell Sutton et al. 2019; Published by Mary Ann Liebert, Inc. This Open Access article is distributed under the terms of the Creative Commons License (http://creativecommons.org/licenses/by/4.0), which permits unrestricted use, distribution, and reproduction in any medium, provided the original work is properly cited. 
of comorbid neck injuries among males and females with concussion, across the life span and by cause of injury.

The important role of a co-occurring (comorbid) neck injury (i.e., injury to the cervical spine region) with concussion is reflected in the latest consensus statement on sports-related concussions. ${ }^{4}$ Literature supports that whiplash-associated disorders and concussions share similar clinical presentations ${ }^{12-16}$ and have been found to commonly co-occur. ${ }^{17}$ In addition, injury to the cervical spine region is particularly vulnerable to concurrent concussion due to its proximity to the head and the lack of protection relative to other regions (i.e., thoracic and lumbosacral) of the spine. ${ }^{18}$ Evidence also supports that females have weaker and anatomically distinct necks than males, ${ }^{19,20}$ which suggests that the relationship between neck injuries and concussions may be sex-dependent and that biological differences between males and females may be responsible for the observed increased vulnerability among females to sustain whiplash in motor vehicle collisions (MVC), ${ }^{21,22}$ poorer prognosis following injury, ${ }^{23,24}$ and increased risk of concussion. ${ }^{25}$

While previous studies on neck injuries and TBI have incorporated sex as a risk factor, ${ }^{26,27}$ they were based on samples with mixed injury severity from major trauma centers and were not population-based. To expand our understanding of neck injury comorbidity at a population level among patients with TBI that are mild in injury severity, a population-based study of all patients with their first concussion-related emergency department (ED) visit in a publicly funded health care system was conducted. Due to the proclivity of concussions and neck injuries in sports and MVC, ${ }^{5-9,21,22}$ this study focused on three distinct populations in the ED: sports-related concussions, MVC-related concussions, and all concussions (regardless of cause of injury). It was hypothesized that the rate of comorbid neck injury among patients in the ED with a concussion diagnosis would be higher among female patients than among male patients, and the magnitude of risk would be age-dependent, controlling for injury-related factors (mechanism, intention of injury [against the injured person]) and other sociodemographic factors (income, rurality of residence). ${ }^{28}$

\section{Materials and Methods}

The Research Ethics Board at the Toronto Rehabilitation Institute-University Health Network (TRI-UHN) and the University of Toronto Research Ethics Board approved this study.

\section{Data source}

Data on ED visits in Ontario, which has a universal health care system that covers all publicly funded health care services, were extracted from the Canadian Institute for Health Information (CIHI) National Ambulatory Care Reporting System (NACRS). ${ }^{29}$ These data were obtained through the Ontario Cancer Data Linkage Program (cd-link). The cd-link is an initiative of the Ontario Institute for Cancer Research/ Cancer Care Ontario Health Services Research Program whereby risk reduced coded data from the Institute for Clinical Evaluative Sciences are provided directly to researchers with the protection of a comprehensive data use agreement.

\section{Sample}

Patients with a first concussion-related ED visit between fiscal years 2002/2003 and 2011/2012 (inclusive) were identified using the International Statistical Classification of Diseases and Related Health Problems, Tenth Revision, Canada (ICD-10-CA) code S06.0 in any of the 10 diagnosis fields in the NACRS. ${ }^{30}$ To maintain sample homogeneity in terms of injury severity, only patients with mild injury severity, as defined by the Abbreviated Injury Score of less than three, ${ }^{31,32}$ were included.

\section{Variables}

Sociodemographic variables included age, sex, income, rurality, and fiscal year of ED discharge. Income and rurality were examined, as previous research suggests that persons of lower socioeconomic status and rural residence have higher rates of ED visits. ${ }^{33-35}$ Fiscal year of ED discharge was also examined to account for the increased awareness of concussion- $/$ brain-related injuries in recent years. ${ }^{36-38}$ Age was categorized into 5-year age groups, ranging from age 0 to 4 years to $85+$ years and treated as an ordinal variable in the logistic models (described below). Sex was categorized as male and female and was the main variable of interest in these models. Income was assessed using five income quintiles, with one representing the lowest and five the highest level of income, adjusted for household size and community. ${ }^{39}$ Rural residence was defined based on the individual's postal code, using the Canadian Postal Code designation for rural. ${ }^{40}$

Injury-related variables included mechanism of injury and intention of injury, which were defined as per the Centers for Disease Control and Prevention Injury Matrix. ${ }^{41}$ Mechanism of injury was categorized into falls, MVC, stuck by/against, other transportation (e.g., pedal cyclist), and other. Intention of injury was categorized as intentional and unintentional. Sports-related concussions were identified and categorized as a binary variable (yes vs. no) using the Association of Public Health Epidemiologists in Ontario (APHEO) definitions of different sports injuries. ${ }^{42}$ Using the definitions stated above, patients in the ED were additionally stratified into those with an MVC-related concussion and those with a sports-related concussion Supplementary Table S5.

The outcome variable was the presence of a comorbid neck injury at the time of the ED visit. This was identified using ICD-10-CA codes S12 to S17 and S19. Superficial injuries of the neck (S10), open wounds of the neck (S11), and traumatic amputation at neck level (S18) were excluded to align with our hypothesis, namely that there may be higher rates of comorbid neck injury among females due to differing neck strength between males and females. Since the ICD-10-CA codes S10 an S11 do not reflect this notion, they were not included in this case definition of comorbid neck injury.

\section{Statistical analyses}

Frequencies and rates of comorbid neck injuries per 100,000 concussion-related ED visits during the study period were determined, stratified by sex and cause of injury (MVC and sports, as defined above regarding injury-related variables). A multivariable logistic regression model was used to measure the odds ratios (ORs) and $95 \%$ confidence interval (CI, Wald) for each of the covariates. All covariates except for age were included as linear terms in the model. Age was modeled as a cubic polynomial, that is, terms for age, age ${ }^{2}$, and age $^{3}$ were included in the model. This is analogous to using a polynomial regression. ${ }^{43,44}$ Since the curves for the 
association between age and rate of comorbid neck injury were different for male and female patients, the model included an interaction term between the effects of age and sex. Due to the fact that the sex and age interaction in the cubic polynomial can be difficult to interpret, a more straightforward depiction of the effect for age and sex was reported by calculating the ORs for each given age group and sex. Tests of significance were two-sided tests with significance levels of $95 \%$. All analyses were conducted using SAS $9.3,{ }^{45}$ and figures in this article were created using $\mathrm{R} 3.4 .1 .^{46}$

\section{Results}

Between fiscal years 2002/2003 and 2011/2012, 90,661 unique individuals were coded with a concussion-related ED visit in Ontario. Patients with missing data of interest (i.e., mechanism of injury, intention of injury, rurality, or income quintile; $N=486$ ) were excluded, leaving 90,175 patients for inclusion, 58\% of whom were males. By cause of injury, 8,134 patients (53\% males) with TBI were in the ED due to an MVC and 30,474 (70\% males) were in the ED due to a sports injury Supplementary Fig. 1 .

Table 1 and Supplementary Table S1 present the sociodemographic and injury-related characteristics of the three samples examined. The rate of comorbid neck injury per 100,000 concussion-related ED visits was higher among females $(4,333$ vs. $2,995 / 100,000)$. This pattern was also observed when the data were stratified by cause of injury $(11,978$ vs. 8,759/100,000 in MVC-related concussions and 4,207 vs. $2,794 / 100,000$ in sports-related concussions). The rate of comorbid neck injury was 2.89 times higher for patients with an MVC-related concussion compared with all concussion-related ED visits (2.92 times higher for males and 2.76 times higher for females). From fiscal years 2002/2003 to 2011/2012, concussion-related diagnoses in the ED setting increased by $19 \%$ among males and $83 \%$ among females while the rate of comorbid neck injury remained relatively stable. However, over this time period, the rate of comorbid neck injury among patients injured via MVC increased by 39\% among males and $29 \%$ among females. Finally, for intentional injuries, the rate of comorbid neck injury was 2.70 times higher for females than for males, whereas only 1.39 times higher for unintentional injuries.

Figure 1 presents the rate of comorbid neck injuries per 100,000 patients with a concussion-related ED visit by 5 -year age groups, sex, and cause of injury (MVC and sports). Females had a higher rate of neck injury compared with males between the ages of 10 and 50 years, after which both males and females had similar rates of comorbid neck injury.

\section{Polynomial logistic regression model}

Figure 2 and Supplementary Table S2 display the results of the cubic polynomial logistic regression model, which produced a moving OR for sex (with males as the referent population) by each 5-year age group. Females had significantly higher odds of sustaining a comorbid neck injury between the ages of 5-49 years for all concussion-related ED visits, 15-49 years for MVC-related concussion ED visits, and 10-39 years for sports-related concussion ED visits, adjusting for all other variables. Patients between the ages of 20 and 24 years had the highest odds of sustaining a comorbid neck injury $(\mathrm{OR}=1.56$ [95\% CI: $1.47-1.80])$, including those injured in an MVC (OR $=1.26$ [95\% CI: 1.27-1.92]) and in sport activities (OR $=1.73$ [95\% CI: 1.42-2.10]). The overall significance of sex in this model was found to be highly significant $(p<0.0001)$ for all three populations using the log-likelihood test.

The ORs and 95\% Wald CI of comorbid neck injuries for all other covariates included in this model are presented in Table 2. Among all patients with a concussion-related ED visit, the odds of a comorbid neck injury among those injured in an MVC was 3.40 times higher than the odds of the same patient who experienced a fall (95\% CI: 3.08-3.76). Other covariates found to be significant for this population included rurality $(\mathrm{OR}=1.21$ [95\% CI: $1.11-1.33])$, sports injury $(\mathrm{OR}=1.24$ [95\% CI: 1.13-1.36]), fiscal year of ED discharge $(\mathrm{OR}=0.98$ [95\% CI: 0.97-0.99]), and intent of injury $(\mathrm{OR}=0.71$ [95\% CI: 0.57-0.87]). Among patients with a sports-related injury, rurality (OR $=1.22$ [95\% CI: 1.04-1.43]) and fiscal year of ED discharge (OR $=0.97$ [95\% CI: 0.950.99]) were significant, with similar trends to that identified in the entire population. No other covariates included in the model for MVC-related concussions were statistically significant.

\section{Discussion}

This study provided evidence that females with a concussionrelated ED visit between the ages of 5 and 49 years had a significantly higher rate of comorbid neck injury than males across all injury contexts (i.e., all concussions, MVC, and sports). This was identified using interaction terms between sex and age, where it was assumed that age did not follow a linear trend, but rather, a cubic trend. This was a unique approach to modeling that, to the best of our knowledge, has not been widely used in other concussion-related research. ${ }^{26,27}$ Future studies on concussions should consider using similar linear and nonlinear sex and age interaction terms across the life span in their models and analysis.

Although results from this study contradict earlier studies by Fujii et al. ${ }^{26}$ and Hasler et al., ${ }^{27}$ these inconsistencies may be attributed to differences in the methodology and sample size, or the selection of patients with differing mechanisms of injury (e.g., trauma center patients). Specifically, the above studies analyzed the rate of cervical spine injury in major trauma patients and reported that females had a lower rate of neck injury $(\mathrm{OR}=0.90$ [95\% CI: $0.84-0.96]$ and $\mathrm{OR}=0.91$ [95\% CI: 0.86-0.96], respectively) compared with males. ${ }^{26,27}$ This study focused on the patients in the ED setting with concussions that are of mild injury severity. As such, findings from our study support increased attention in the ED setting for a potential neck injury among females, aged 5-49 years, with a concussion (particularly those between 15 and 49 years of age with an MVC-related concussion and those between 10 and 39 years of age for a sportsrelated concussion), to allow for early intervention and treatment. In particular, further work is required to determine the potential anatomical and biological differences that underlie the apparent increased rate of comorbid neck injuries among females with a concussion. Given that neck injury in TBI has been linked to persistent postconcussive symptoms such as dizziness, unsteadiness, gaze stability, and head-eye coordination, ${ }^{12-16,47-49}$ future efforts should explore sexspecific differences in these postconcussive symptoms and its impact on injury severity, recovery time, intervention, and 


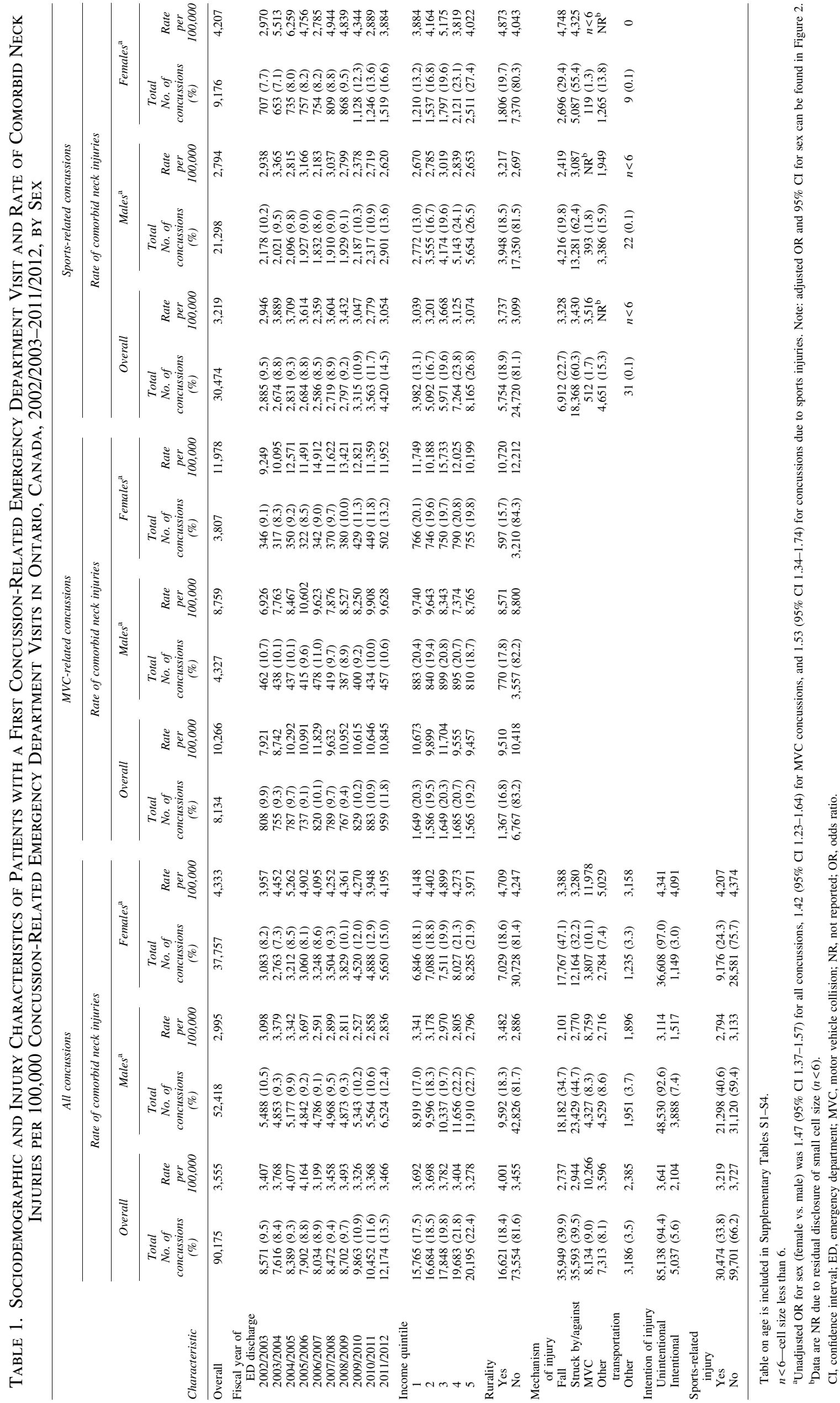



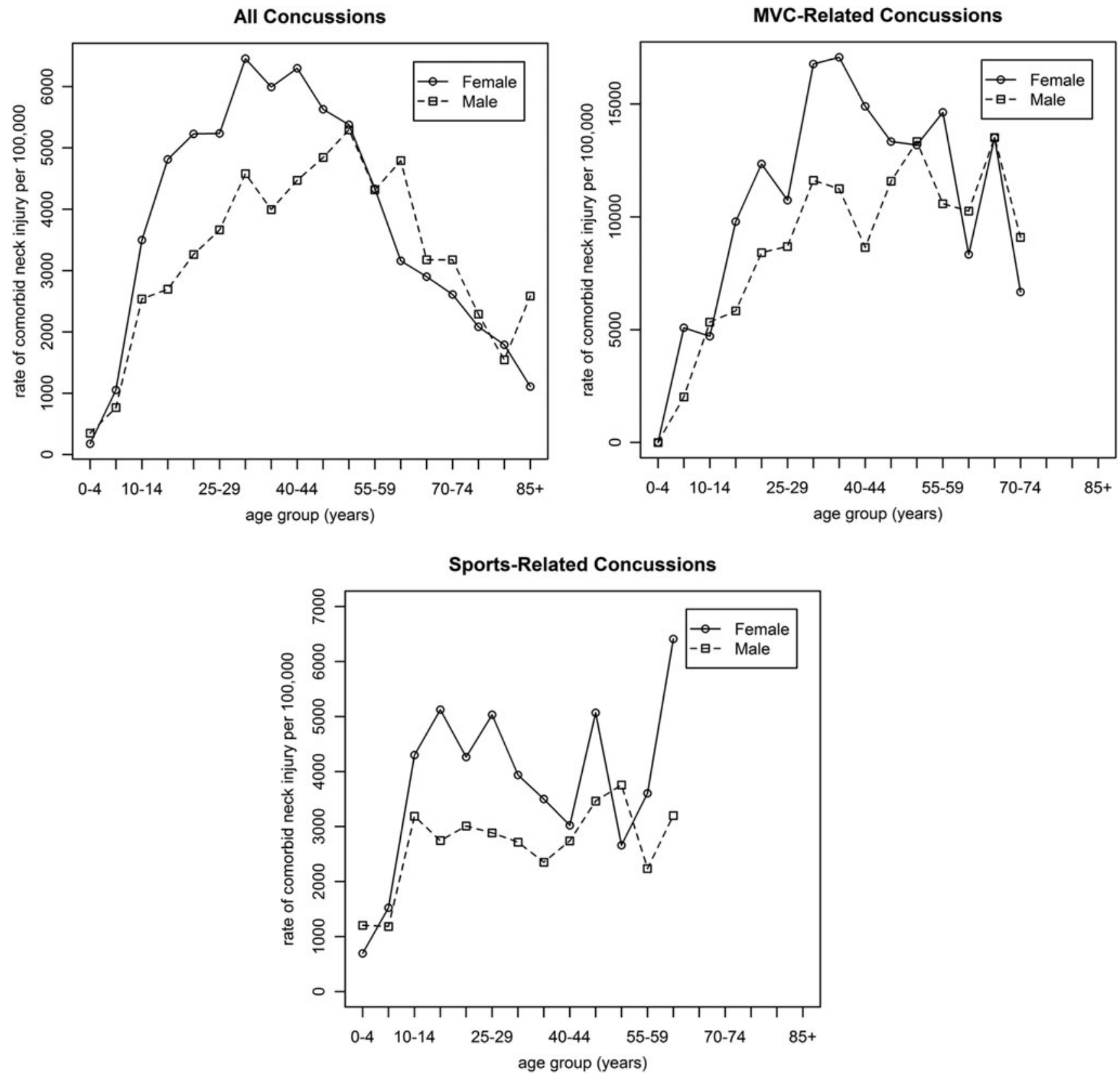

FIG. 1. Rates of comorbid neck injury per 100,000 concussion-related emergency department visits in Ontario, Canada, 2002/2003-2011/2012, by 5-year age groups, sex, and cause of injury. The rates of neck injuries for the age group 70-74 years for MVC-related concussions and age group 60-64 years for sports-related concussions were not reported due to small sample size. MVC, motor vehicle collision.

the rehabilitation process to support appropriate care and management for patients. ${ }^{50,51}$

This study found that females, aged 15-49 years, who were injured in an MVC had significantly higher odds of comorbid neck injury, which may reflect the fact that individuals are not legally allowed to drive until the age of 16 in Ontario. ${ }^{52} \mathrm{Si}-$ milarly, our results indicated that females, aged 10-39 years, who were injured in a sports-related activity, had significantly higher odds of a comorbid neck injury compared with males, possibly reflecting a participation in sports among younger adults. $^{53}$ These findings encourage additional research to understand how best to prevent head and neck injuries for this population, including sex-specific prevention or harm reduc- tion strategies such as improving protective equipment in sports for both males and females, and safety measures for motor vehicle drivers, occupants, or cyclists.

Data on other hypothesized variables, including mechanism and cause of injury (i.e., MVC, sports injuries) and residence in rural neighborhoods, were significantly associated with neck injury comorbidity in all concussion-related ED visits, holding all other variables constant. This is consistent with previous studies, which reported higher odds of sustaining a neck injury in MVC and sports-related incidents compared with all concussion-related injuries. ${ }^{17,21,22,54}$ Furthermore, the results of our study suggest that females have a higher risk of sustaining a comorbid neck injury across all causes of injury. 
All Concussions

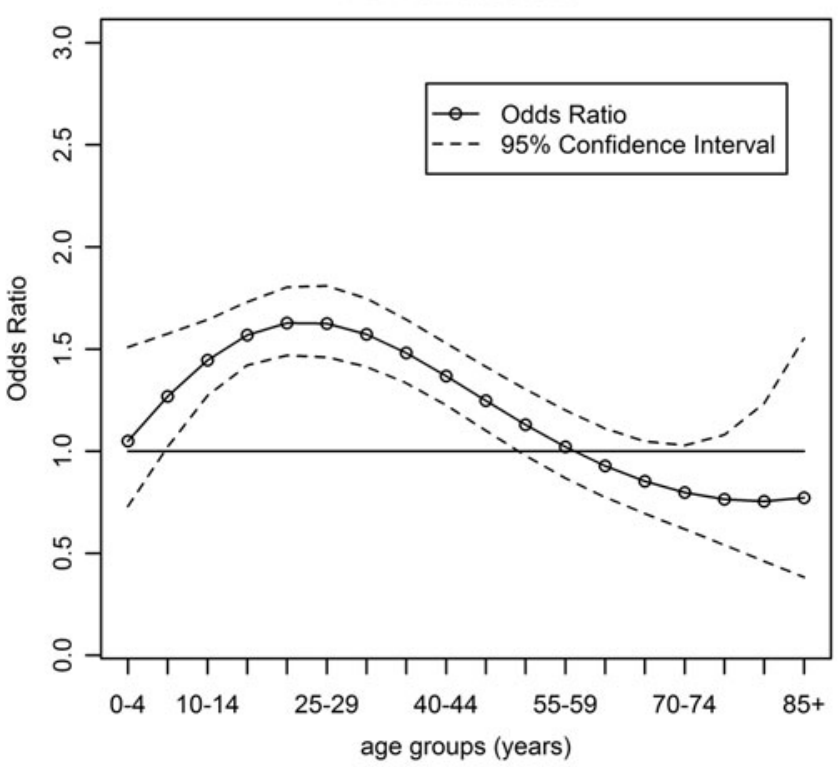

MVC-Related Concussions

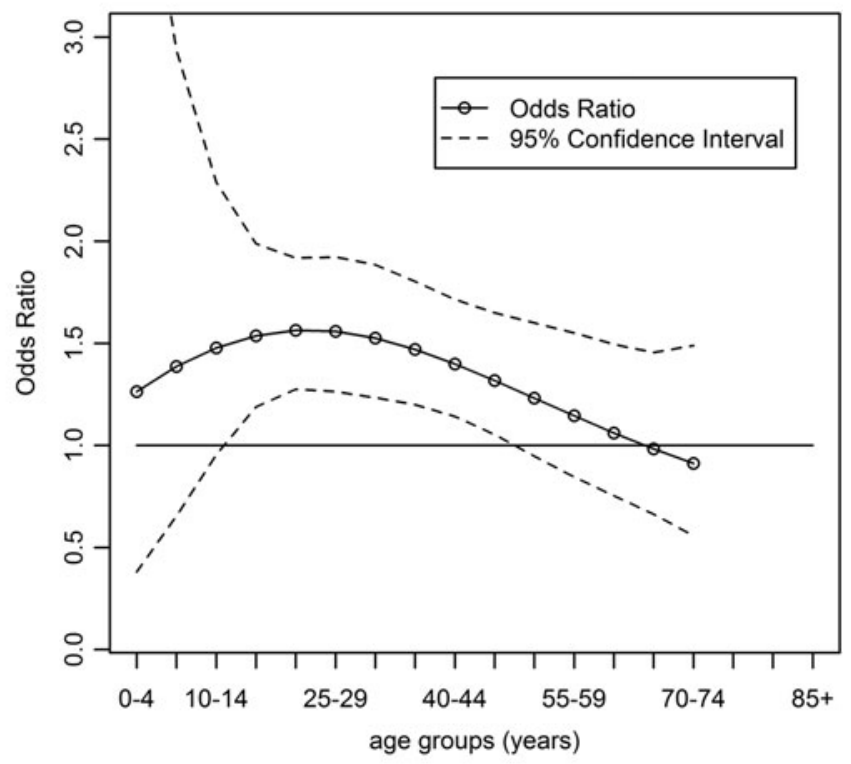

Sports-Related Concussions

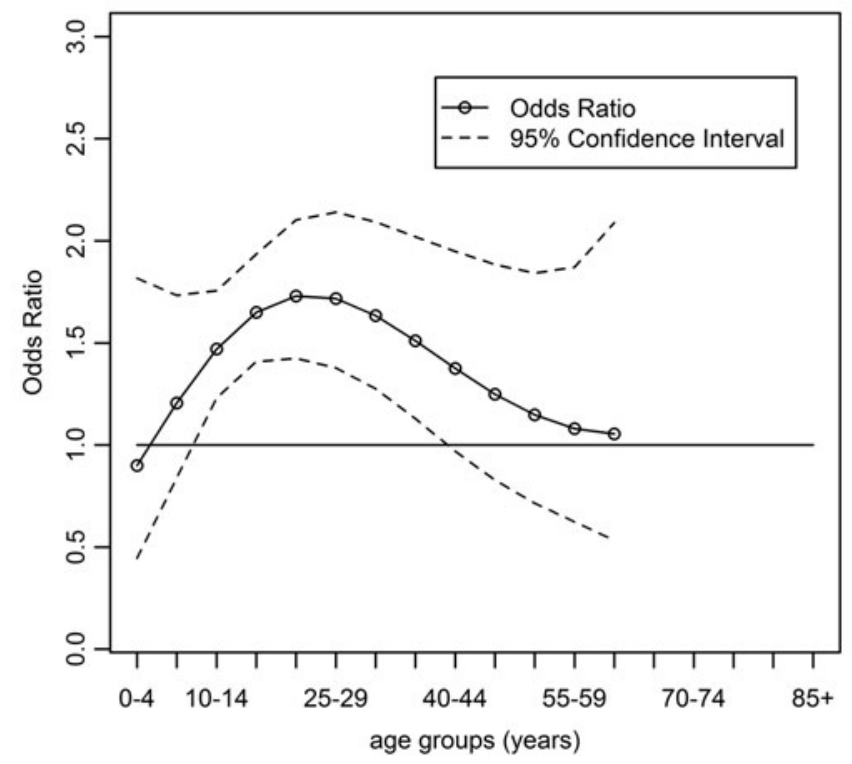

FIG. 2. Odds ratio and $95 \%$ confidence interval of sex (reference $=$ male) of comorbid neck injury among patients with a concussion-related emergency department visits in Ontario, Canada, 2002/2003-2011/2012, by age groups and cause of injury. The rates of neck injuries for the age group 70-74 years for MVC-related concussions and age group 60-64 years for sports-related concussions were not reported due to small sample size.

Additionally, our study indicates that although overall rates for neck injury were lower for intentional injuries, females who suffer a concussion from an intentional injury may have a rate of comorbid neck injury that is higher than that of males. These findings further support a sex-specific approach to study and analyze concussion data, particularly females whose injury is a result of assault/violence.

\section{Strengths and limitations}

One of the main strengths of this study was the use of a population-based data set, the NACRS, from a publicly funded health system to identify all ED visits in the province of Ontario, home to $\sim 40 \%$ of the Canadian population. ${ }^{55}$ Use of these data eliminated some of the inherent issues previously identified (i.e., insurance bias, attrition) in studying neck injury comorbidity in concussion-related ED visits within nonpublicly funded health care systems. Our study is the first, to the best of our knowledge, to highlight the critical influence of age and sex on neck injury comorbidity in concussion-related ED visits across the life span. We used a novel method of modeling the variable age with a cubic trend and as an interaction term with sex, whereas previous related studies assumed linear trends for these covariates. ${ }^{26,27}$ Such an approach is the optimal methodology in situations where male and female sex exerts differential influence on the outcome variable (in this instance, 


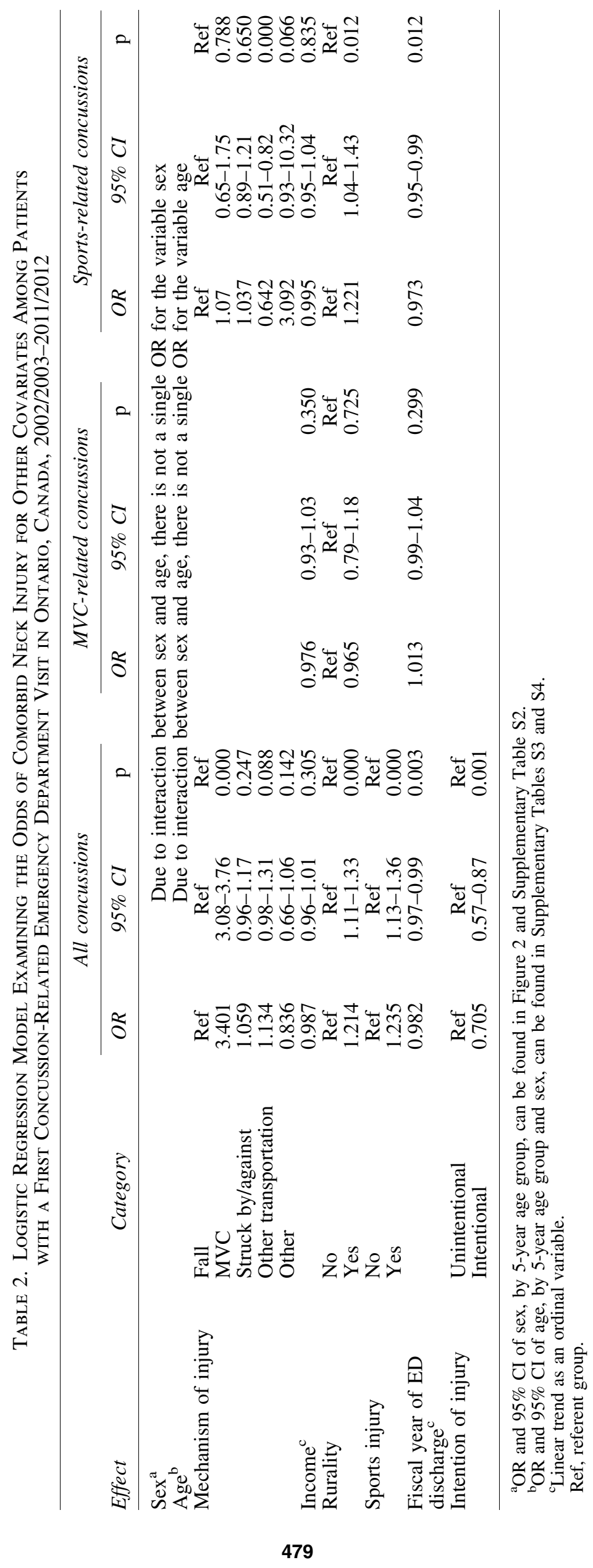


neck injury comorbidity) across different age groups. Finally, previous studies included patients with TBI that range in severity from mild to severe ${ }^{26,27}$; this study reduced the risk of selection bias by only analyzing patients with concussionrelated ED visits and mild severity.

A recognized limitation of this study was that the number of patients with a first concussion may be underestimated, as the data set excluded patients with a concussion who (a) did not visit the ED, but instead sought care from a family physician or an acute care setting; (b) did not seek any care at all; or (c) were not diagnosed with an ICD-10-CA S06.0 code. Therefore, this study may suffer from potential selection bias, as only data on ED visits were included. We also adopted a conservative ICD-10-CA case definition for concussion injury, which was also used by other investigators. ${ }^{56}$ As a result, it is possible that concussions may have been missed in the emergency room or were coded under other ICD-10-CA codes such as "unspecified injuries to the head." An additional limitation was that our study only included patients with their first concussion-related ED visit between 2002/ 2003 and 2011/2012; therefore, we were unable to determine if they had concussion-related visits before the study period. Limitations associated with health administrative data were also recognized (e.g., variables of interest may have been unavailable, missed diagnosis due to coding). Also, it is acknowledged that this study examined age using 5-year age groups, which may not be adequate to detect differences in younger populations. Furthermore, it was not possible to determine from health administrative data how these findings may have been influenced by gender differences in reporting concussion. ${ }^{57-59}$ Finally, we recognize that the literature on concussion in older adults is understudied and our finding may reflect that lack of concussion protocols and complexity regarding the identification of comorbidities in this population. ${ }^{60}$ Despite these limitations, elucidation of sex differences in neck injury comorbidity across the life span could have a tremendous impact on how neck injuries are viewed and managed among patients with a concussion in the future.

\section{Conclusions}

This study showed an increased risk of comorbid neck injury in females with a concussion-related ED visit, which has strong implications for patients, clinicians, and decision-makers. While there has been increased awareness of concussions in the media in recent years, especially sports-related concussions, ${ }^{54}$ this study supports the hypothesis that neck injuries and concussions, which have similar symptoms, ${ }^{12-16}$ frequently cooccur. ${ }^{17}$ Therefore, our findings support the need for increased consideration of comorbid neck injuries to allow for early intervention, particularly for females, who have been found to be most at risk for persistent symptoms. ${ }^{10,11}$ Most importantly, the results of this study suggest that the biological differences between males and females, ${ }^{19,20}$ which determine the risk of comorbid neck injury, are age-dependent. This study showed a clear interaction between age and sex and, therefore, it is crucial to consider linear and nonlinear sex and age interactions across the life span of patients in future studies on concussions.

\section{Acknowledgments}

Special thanks to Sandra Sokoloff for her comments and assistance in the editing process of the article. Research re- ported in this publication was supported by the Eunice Kennedy Shriver National Institute of Child Health and Human Development of the National Institutes of Health under Award Number R21HD089106. The content is solely the responsibility of the authors and does not necessarily represent the official views of the National Institutes of Health. A.C. was funded by the Canadian Institutes of Health Research (CIHR) Chair in Gender, Work and Health (grant no. CGW-126580). T.M. was supported by the Alzheimer's Association Grant (AARF-16-442937).

\section{Disclaimer}

This study was supported through the provision of data by the Institute for Clinical Evaluative Sciences (ICES) and Cancer Care Ontario (CCO) and through funding support to ICES from an annual grant by the Ministry of Health and Long-Term Care (MOHLTC) and the Ontario Institute for Cancer Research (OICR). The opinions, results, and conclusions reported in this article are those of the authors and are independent of the funding sources. No endorsement by ICES, CCO, OICR, or the Government of Ontario is intended or should be inferred. Parts of this material are based on data and information compiled and provided by CIHI. However, the analyses, conclusions, opinions, and statements expressed herein are those of the author and not necessarily those of CIHI.

\section{Authors' Contributions}

All authors conceptualized and designed the study. M.S. and Dr. M.E. formulated the methods for statistical analyses. M.S. conducted the statistical analyses and drafted the initial article. All authors reviewed the article, had significant input into the editing and interpretation of data, and read and approved the final article.

\section{Author Disclosure Statement}

No author has a conflict of interest, and we certify that no party has a direct interest in the result of this research or has conferred or will confer a benefit on us or any organization with which we are associated.

\section{References}

1. Taylor CA. Traumatic brain injury-related emergency department visits, hospitalizations, and deaths_-United States, 2007 and 2013. MMWR Surveill Summ 2017;66:1-16.

2. Coronado VG, McGuire LC, Sarmiento K, et al. Trends in traumatic brain injury in the US and the public health response: 1995-2009. J Safety Res 2012;43:299-307.

3. Faul M, Coronado V. Epidemiology of traumatic brain injury. Handb Clin Neurol 2015;127:3-13.

4. McCrory P, Meeuwisse W, Dvorak J, et al. Consensus statement on concussion in sport-The 5th international conference on concussion in sport held in Berlin, October 2016. Br J Sports Med 2017;51:838-847.

5. Hootman JM, Dick R, Agel J. Epidemiology of collegiate injuries for 15 sports: Summary and recommendations for injury prevention initiatives. J Athl Train 2007;42:311.

6. Gessel LM, Fields SK, Collins CL, Dick RW, Comstock RD. Concussions among United States high school and collegiate athletes. J Athl Train 2007;42:495. 
7. Covassin T, Swanik CB, Sachs ML. Sex differences and the incidence of concussions among collegiate athletes. J Athl Train 2003;38:238.

8. Marar M, McIlvain NM, Fields SK, Comstock RD. Epidemiology of concussions among United States high school athletes in 20 sports. Am J Sports Med 2012;40:747-755.

9. Lincoln AE, Caswell SV, Almquist JL, Dunn RE, Norris JB, Hinton RY. Trends in concussion incidence in high school sports: A prospective 11-year study. Am J Sports Med 2011;39:958-963.

10. Iverson GL, Gardner AJ, Terry DP, et al. Predictors of clinical recovery from concussion: A systematic review. $\mathrm{Br}$ J Sports Med 2017;51:941-948.

11. Covassin T, Savage JL, Bretzin AC, Fox ME. Sex differences in sport-related concussion long-term outcomes. Int $\mathrm{J}$ Psychophysiol 2018;132(Pt A):9-13.

12. Elkin BS, Elliott JM, Siegmund GP. Whiplash injury or concussion? A possible biomechanical explanation for concussion symptoms in some individuals following a rearend collision. J Orthop Sports Phys Ther 2016;46:874-885.

13. Leslie O, Craton N. Concussion: Purely a brain injury? Clin J Sport Med 2013;23:331-332.

14. Hecht JS. Occipital nerve blocks in postconcussive headaches: A retrospective review and report of ten patients. J Head Trauma Rehabil 2004;19:58-71.

15. Leddy JJ, Baker JG, Merchant A, et al. Brain or strain? Symptoms alone do not distinguish physiologic concussion from cervical/vestibular injury. Clin J Sport Med 2015;25: 237-242.

16. Morin M, Langevin P, Fait P. Cervical spine involvement in mild traumatic brain injury: A review. J Sports Med (Hindawi Publ Corp) 2016;2016:1590161.

17. Hynes LM, Dickey JP. Is there a relationship between whiplash-associated disorders and concussion in hockey? A preliminary study. Brain Inj 2006;20:179-188.

18. Ahuja CS, Wilson JR, Nori S, et al. Traumatic spinal cord injury. Nat Rev Dis Primers 2017;3:17018.

19. Catenaccio E, Mu W, Kaplan A, et al. Characterization of neck strength in healthy young adults. PM R 2017;9:884891.

20. Vasavada AN, Danaraj J, Siegmund GP. Head and neck anthropometry, vertebral geometry and neck strength in height-matched men and women. J Biomech 2008;41:114 121.

21. Quinlan KP, Annest JL, Myers B, Ryan G, Hill H. Neck strains and sprains among motor vehicle occupantsUnited States, 2000. Accid Anal Prev 2004;36:21-27.

22. Stemper BD, Corner BD. Whiplash-associated disorders: Occupant kinematics and neck morphology. J Orthop Sports Phys Ther 2016;46:834-844.

23. Walton DM, Pretty J, MacDermid JC, Teasell RW. Risk factors for persistent problems following whiplash injury: Results of a systematic review and meta-analysis. J Orthop Sports Phys Ther 2009;39:334-350.

24. McClune T, Burton AK, Waddell G. Whiplash associated disorders: A review of the literature to guide patient information and advice. Emerg Med J 2002;19: 499-506.

25. Collins CL, Fletcher EN, Fields SK, et al. Neck strength: A protective factor reducing risk for concussion in high school sports. J Prim Prev 2014;35:309-319.

26. Fujii T, Faul M, Sasser S. Risk factors for cervical spine injury among patients with traumatic brain injury. J Emerg Trauma Shock 2013;6:252-258.
27. Hasler RM, Exadaktylos AK, Bouamra O, et al. Epidemiology and predictors of cervical spine injury in adult major trauma patients: A multicenter cohort study. J Trauma Acute Care Surg 2012;72:975-981.

28. Social Determinants of Health. Public Health Agency of Canada. 2016. Available at: http://cbpp-pcpe.phac-aspc.gc .ca/public-health-topics/social-determinants-of-health Accessed August 4, 2017.

29. Emergency and Ambulatory Care. 2017. Available at: https:// www-cihi-ca.myaccess.library.utoronto.ca/en/emergency-andambulatory-care Accessed July 7, 2017.

30. Barker-Collo S, Theadom A, Jones K, Feigin VL, Kahan M. Accuracy of an International Classification of Diseases code surveillance system in the identification of traumatic brain injury. Neuroepidemiology 2016;47:46-52.

31. Abbreviated Injury Scale. Available at: www.trauma.org/ archive/scores/ais.html Accessed November 24, 2017.

32. Saverino C, Swaine B, Jaglal S, et al. Rehospitalization after traumatic brain injury: A population-based study. Arch Phys Med Rehabil 2016;97:S19-S25.

33. Faelker T, Pickett W, Brison RJ. Socioeconomic differences in childhood injury: A population based epidemiologic study in Ontario, Canada. Inj Prev 2000;6:203-208.

34. Kmet L, Macarthur C. Urban-rural differences in motor vehicle crash fatality and hospitalization rates among children and youth. Accid Anal Prev 2006;38:122-127.

35. Dryden DM, Saunders LD, Rowe BH, et al. The epidemiology of traumatic spinal cord injury in Alberta, Canada. Can J Neurol Sci 2003;30:113-121.

36. Sarmiento K, Hoffman R, Dmitrovsky Z, Lee R. A 10-year review of the Centers for Disease Control and Prevention's Heads Up initiatives: Bringing concussion awareness to the forefront. J Safety Res 2014;50:143.

37. Provvidenza C, Engebretsen L, Tator C, et al. From consensus to action: Knowledge transfer, education and influencing policy on sports concussion. Br J Sports Med 2013; 47:332-338.

38. Cournoyer J, Tripp BL. Concussion knowledge in high school football players. J Athl Train 2014;49:654-658.

39. Glazier RH, Zagorski BM, Rayner J. Comparison of primary care models in Ontario by demographics, case mix and emergency department use, 2008/09 to 2009/10. Toronto, Ontario, Canada: Institute for Clinical Evaluative Sciences, 2012.

40. Du Plessis V, Beshiri R, Bollman R, Clemenson H. Rural and small town Canada analysis bulletin. Ottawa, Canada: Statistics Canada, 2001.

41. ICD Injury Matrices. 2017. Available at: https://www.cdc .gov/nchs/injury/injury_tools.htm Accessed June 15, 2017.

42. Suzanne Fegan CB, Dhar B, Herring J, et al. Recommended ICD-10-CA codes for injury core indicators. 2013. Available at: http://core.apheo.ca/index.php?pid=306 Accessed May 18, 2017.

43. Kleinbaum DGK, Lawrence L, Muller KE, N A. Applied regression analysis and other multivariate methods. Pacific Grove, CA: Duxbury Press, 1998.

44. Weisberg S. Applied linear regression. New York: John Wiley \& Sons, 1985.

45. SAS 9.3. SAS Institute. Available at: https://www.sas.com/ en_ca/software/base-sas.html Accessed December 17, 2018.

46. R 3.4.1. R Project. Available at: https://www.r-project.org/ Accessed December 17, 2018.

47. Mallinson AI, Longridge NS. Dizziness from whiplash and head injury: Differences between whiplash and head injury. Otol Neurotol 1998;19:814-818. 
48. Treleaven J. Dizziness, unsteadiness, visual disturbances, and postural control: Implications for the transition to chronic symptoms after a whiplash trauma. Spine 2011;36:S211-S217.

49. Treleaven J, Jull G, Grip H. Head eye co-ordination and gaze stability in subjects with persistent whiplash associated disorders. Man Ther 2011;16:252-257.

50. Cheever K, Kawata K, Tierney R, Galgon A. Cervical injury assessments for concussion evaluation: A review. J Athl Train 2016;51:1037-1044.

51. Langelier DM, Schneider KJ, Hurlbert J, Debert CT: The importance of a neck exam in sport-related concussion: Cervical schwannoma in post concussion syndrome. Phys Ther Sport 2017;25:84-88.

52. Ministry of Transportation. The Official Ministry of Transportation (MTO) Driver's Handbook. Available at: https:// www.ontario.ca/document/official-mto-drivers-handbook Accessed August 10, 2017.

53. Statistics Canada. Sport participation 2010: Research paper. Canada: Canadian Heritage, 2013.

54. Proctor MR, Cantu RC. Head and neck injuries in young athletes. Clin Sports Med 2000;19:693-715.

55. Statistics Canada. Population by year, by province and territory (Proportion). 2017. Available at: /www.statcan.gc .ca/tables-tableaux/sum-som/101/cst01/demo02d-eng.htm Accessed November 21, 2017.

56. Zemek RL, Grool AM, Duque DR, et al. Annual and seasonal trends in ambulatory visits for pediatric concussion in
Ontario between 2003 and 2013. J Pediatr 2017;181:222_228.e222.

57. Courtenay WH. Constructions of masculinity and their influence on men's well-being: A theory of gender and health. Soc Sci Med 2000;50:1385-1401.

58. Springer KW, Mouzon DM. "Macho men" and preventive health care: Implications for older men in different social classes. J Health Soc Behav 2011;52:212-227.

59. Williams DR. The health of men: Structured inequalities and opportunities. Am J Pub Health 2008;98:S150-S157.

60. Gardner RC, Dams-O'Connor K, Morrissey MR, Manley G. Geriatric traumatic brain injury: Epidemiology, outcomes, knowledge gaps, and future directions. J Neurotrauma 2018. [Epub ahead of print]; DOI: 10.1089/neu.2017.5371.

Address correspondence to: Angela Colantonio, PhD Rehabilitation Sciences Building University of Toronto 500 University Avenue Suite 160 Toronto, ON M5G 1 V7 Canada

E-mail: angela.colantonio@utoronto.ca 